\title{
Avalanches overflowing a dam: dead zone, granular bore and run-out shortening
}

\author{
Thierry FAUG, Benoit CHANUT, Mohamed NAAIM, Bertrand PERRIN \\ Cemagref Grenoble, UR ETNA, 2 rue de la Papeterie, BP 76, 38402 Saint-Martin-d'Hères-Cedex, France \\ E-mail: thierry.faug@cemagref.fr
}

\begin{abstract}
The influence of a dam on granular avalanches was investigated. Small-scale laboratory experiments were designed to study the effectiveness of dams built to protect against large-scale dense snow avalanches. These experiments consisted of releasing a granular mass that first flowed down an inclined channel, then hit and overflowed a dam spanning the channel exit and finally spread out on an inclined unconfined run-out zone. First, we measured the volume retained upstream of the obstacle and the overrun length downstream of the obstacle. In the avalanche regime studied here, no simple relation was found between the volume retained and the run-out shortening resulting from the obstacle. The results highlighted that the avalanche run-out was also shortened by complex local energy dissipation. Second, we report the study of the granular deposit propagating upstream of the dam. We show that there was a change in behaviour from an overflow-type regime for low dam heights to a bore regime for higher dam heights. Finally, we show that this change in behaviour directly influenced the local energy dissipation and the resulting avalanche run-out shortening downstream of the dam.
\end{abstract}

\section{INTRODUCTION}

One method of protecting mountainous areas against dense snow avalanches is to build passive defence structures in the run-out zone of the snow avalanche in order to divert, brake and stop the avalanche. Many studies have been conducted over the last few years in order to analyze the effectiveness of different protection structures against snow avalanches. Several approaches have been used: (1) full-scale observations of snow avalanches interacting with defence structures (Larsen and Norem, 1996; Harbitz and others, 2000; Jóhannesson, 2001; Lied and others, 2002; Cui and others, 2007); (2) smallscale laboratory experiments with granular flows (Chu and others, 1995; Hákonardóttir and others, 2001, 2003a; Faug and others, 2002, 2003, 2004a; Platzer and others, 2004) and, to a lesser extent, in situ chute experiments with snow flows (Hákonardóttir and others, 2003b; Faug and others, 2007); and (3) numerical simulations (Naaim, 1998; Chiou and others, 2005). Other studies combined numerical simulations or theoretical models with full-scale terrain observations (McClung and Mears, 1995; Domaas and Harbitz, 1998; Harbitz and others, 2000; Cui and others, 2007) or with laboratory experiments (McClung and Mears, 1995; Tai and others, 2001; Gray and others, 2003; Naaim and others, 2003, 2004; Faug and others, 2004b).

In many previous studies reported in the literature (e.g. Chu and others, 1995; Tai and others, 2001; Faug and others, 2003; Hákonardóttir and others, 2003a; Chiou and others, 2005; Gray and Cui, 2007), dense snow avalanches interacting with protection dams are regarded as granular avalanches flowing over obstacles. Here we present new small-scale laboratory experiments on granular avalanches hitting and overflowing a dam. These experiments were carried out on the granular experimental platform at Cemagref, Grenoble, France. The effectiveness of protection dams against full-scale dense snow avalanches was investigated.

This new platform consists of two inclined planes. The upstream plane is equipped with two side-walls constituting a channel. A dam normal to the bottom of the plane can be set up to span the exit of the channel. The main objective of these experiments was to investigate the run-out shortening of the granular avalanche downstream of the dam and the final volume retained upstream of the dam. Furthermore, a video camera was set up at one side-wall of the channel for a detailed study of the formation of the deposit upstream of the dam and its propagation. If the dam was sufficiently high, we observed that the deposition process could generate a granular jump propagating increasingly far upstream as the dam height increased.

The experimental set-up and procedure are first presented. We then present the main results concerning (1) the run-out shortening and (2) the deposition process. Finally, we show that the observed deposition process directly influences the local energy dissipation caused by the dam. This consequently shortens the maximum run-out of the granular avalanche downstream of the dam.

\section{EXPERIMENTAL SET-UP}

The experimental set-up consists of two inclined planes covered with rough sandpaper (Fig. 1). The granulometry (mean value of $0.5 \mathrm{~mm}$ ) of the sandpaper was close to the diameter of the flowing particles $(1 \mathrm{~mm})$. In our experiments, we fixed certain conditions: (1) the upstream plane was inclined at $32^{\circ}$ and was equipped with a $1.60 \mathrm{~m}$ long and $20 \mathrm{~cm}$ wide channel with an upstream reservoir to store the granular material before releasing it, and (2) the downstream plane was inclined at $20^{\circ}$.

The preliminary tests investigated the granular avalanche without a dam. A granular mass $\left(m_{0}=10 \mathrm{~kg}\right)$ of glass beads, with a mean diameter of $1 \mathrm{~mm}$ and a particle density $\rho_{\mathrm{P}}=$ $2450 \mathrm{~kg} \mathrm{~m}^{-3}$, was released by opening the reservoir gate. The granular mass then flowed down the channel and decelerated before spreading out on the unconfined run-out zone.

Using a video camera at one side-wall, we measured the changes in flow depth at the exit of the channel over time. Figure $2 \mathrm{~b}$ shows flow depth vs time. A maximum was reached 


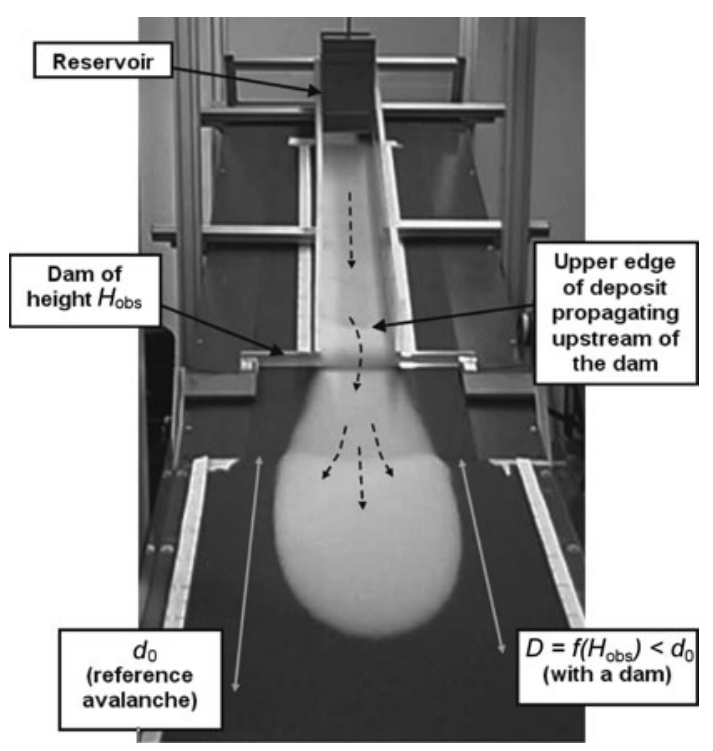

Fig. 1. The experimental granular platform with a granular avalanche overflowing a dam before stopping downstream of the obstacle.

and defined as the reference flow depth $h_{0}$. Furthermore, using a video camera above the channel, we measured the front position of the granular mass $x_{\text {front }}$ in the last third of the channel. The changes over time are illustrated by a straight line in Figure 2a, which allowed us to define a reference front velocity $u_{0}$. The maximum run-out distance $d_{0}$ of the granular avalanche was defined as the final deposit length measured from the beginning of the downstream plane inclined at $20^{\circ}$ (see Fig. 1). The following values were retained to characterize the reference avalanche: (1) the front velocity $u_{0}=1.28 \mathrm{~m} \mathrm{~s}^{-1}$; (2) the flow depth $h_{0}=14 \mathrm{~mm}$; and (3) the maximum run-out distance $d_{0}=88.3 \mathrm{~cm}$, allowing us to deduce the Froude number $\mathrm{Fr}=u_{0} / \sqrt{\mathrm{g} h_{0} \cos 32^{\circ}}=3.75$.

The subsequent experiment consisted of releasing the same granular mass with a dam spanning the channel exit. The dam was used to model a protection dam that would be overflowed by a snow avalanche. In these experiments, the granular mass hit the dam and overflowed before spreading out on the downstream inclined plane. We analyzed the influence of varying dam height $H_{\mathrm{obs}}$ on the maximum runout $D$ downstream of the obstacle, the final mass retained upstream of the dam, $m_{\mathrm{s}}$, and the changes in the free surface in the vicinity of the obstacle over time.

\section{RESULTS ON RUN-OUT SHORTENING}

A previous study (Faug and others, 2003) showed that in a regime of slow flow, the run-out shortening caused by a dam is completely dependent upon the volume of granular mass retained upstream of the dam. The slow-flow regime is characterized by a Froude number close to 1 and the existence of a steady and uniform regime in the channel (i.e. constant flow depth over time and space over a long distance), similar to the regime investigated for inclined planes in GDR MiDi (2004). In this regime, the run-out shortening is represented by the straight line $y=x$ in Figure $3 a$, i.e.

$$
\frac{D}{d_{0}}=\left(1-\frac{V_{s}}{V_{0}}\right)^{1 / 3}
$$
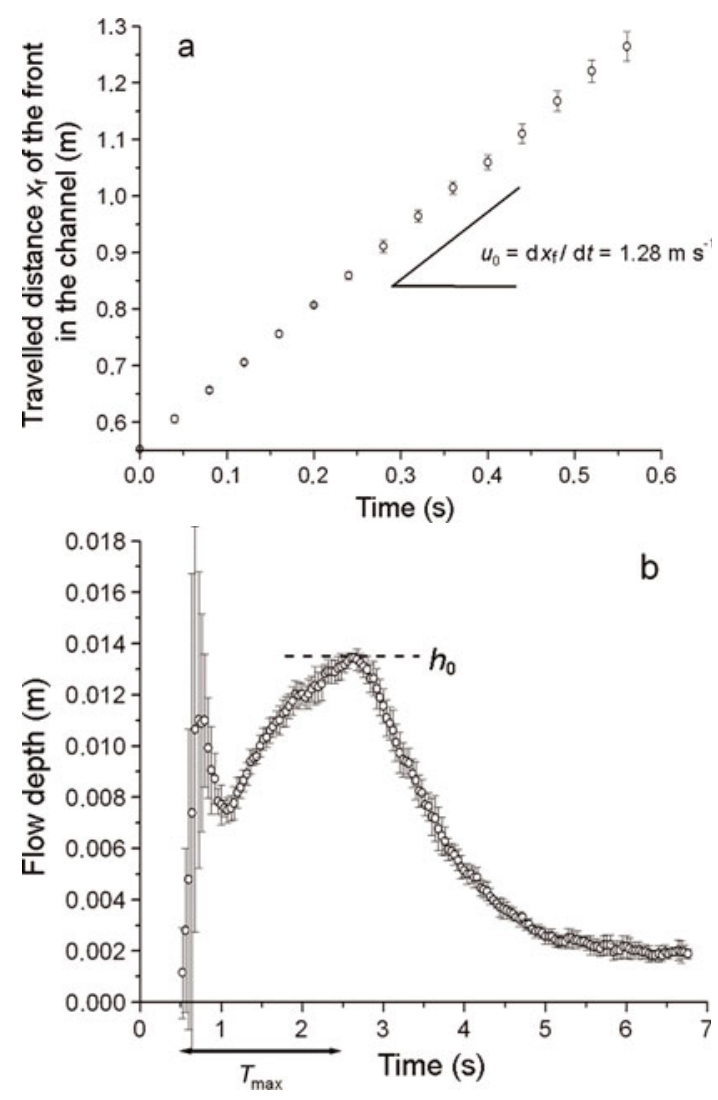

Fig. 2. (a) Front position vs time in the channel and (b) flow depth vs time at the exit of the channel. The time $T_{\max }$ is the time between front arrival and the maximum flow depth $h_{0}$. The initally large error bars are due to particles in saltation that make it difficult to estimate the flow depth in the dilute front.

where $V_{0}=m_{0} / \rho$ and $V_{\mathrm{s}}=m_{\mathrm{s}} / \rho$ are the initial volume released and the volume retained upstream of the dam, respectively, and $\rho$ is the bulk density of the granular medium.

The bulk density is $\rho=\phi \rho_{P}$, and a volume fraction of $\phi=0.6$ is assumed. The avalanche regime that we studied in this investigation was characterized by a Froude number significantly greater than 1 , and a non-steady and non-uniform state. In this regime, Equation (1) is no longer valid. Indeed, as is illustrated in Figure 3, the run-out shortening term $D / d_{0}$ is always smaller than the volume reduction term $\left(1-V_{s} / V_{0}\right)^{1 / 3}$, whatever the dam height. We interpret the difference between the latter and the former term as the contribution from complex local energy dissipation. This difference is referred to as $f$, i.e.

$$
f=\left(1-\frac{V_{s}}{V_{0}}\right)^{1 / 3}-\frac{D}{d_{0}} .
$$

Figure $3 \mathrm{~b}$ depicts $f$ vs the dam height normalized by the reference flow depth $\left(H_{\text {obs }} / h_{0}\right)$. In the regime of slow flow, the function $f$ vanishes by virtue of Equation (1) (Faug and others, 2003). In a purely inertial regime (very rapid flow with $\mathrm{Fr} \approx 10$ ), very little material is expected to be retained upstream of the dam. The function $f$ is then expected to be equal to the run-out shortening expressed in the form $1-D / d_{0}\left(V_{\mathrm{s}}=0\right.$ in Equation (2)).

We also reported one straight line (dashed line in Fig. 3a) representing the expected trend in such a regime for low dams, where local energy dissipation is expected to be 
greater than in our experiments (intermediate Froude number). Note that even in this regime there might be a critical dam height $H_{\mathrm{C}}(\mathrm{Fr} \gg 1)$ that would retain all granular material so that $f$ would fall back to 0 as $H_{\text {obs }}$ approaches this critical height. We arbitrarily report this critical height $H_{\mathrm{C}}(\mathrm{Fr} \gg 1)$ in Figure $3 \mathrm{~b}$. Note that $H_{\mathrm{C}}(\mathrm{Fr} \gg 1)$ is expected to increase with increasing $\mathrm{Fr}$.

Figure $3 \mathrm{~b}$ shows the variation of $f$ as a function of $H_{\text {obs }} / h_{0}$ obtained from our experiments. This variation corresponds to an intermediate case between the two extreme regimes mentioned above (slow-flow regime and inertial regime). Two comments are necessary regarding Figure $3 \mathrm{~b}$. First, when the ratio $H_{\text {obs }} / h_{0}$ is greater than 5 , the function $f$ rapidly decreases. This asymptotic behaviour for high dams results from the large amount of granular material retained upstream of the dam, which tends towards the volume initially released, i.e. $V_{s} / V_{0} \rightarrow 1$. Here we reached a regime for which the contribution of local energy dissipations becomes very weak in terms of run-out shortening. Secondly, the function $f$ shows an inflection point towards $H_{\mathrm{obs}} / h_{0} \approx 3$. This major point is analyzed in detail in section 4.

Knowledge of $d_{0}$ (run-out without dam) and $V_{\mathrm{s}}$ (volume retained upstream of the dam) is needed to determine the function $f$. Note that a comparison of the small-scale experiments using granular materials from the literature with the observations from full-scale snow avalanches overtopping a dam was recently proposed by Faug and others (in press). This study showed that a simple scaling connecting the maximum run-out normalized by the obstacle height, $D / H_{\text {obs, }}$ and the incoming kinetic energy normalized by the obstacle height, $u_{0}^{2} /\left(2 g H_{\text {obs }}\right)$,

$$
\frac{D}{H_{\text {obs }}}=a_{1} \frac{u_{0}^{2}}{2 g H_{\text {obs }}}+a_{0},
$$

where $a_{1}$ and $a_{0}$ are fitting parameters, could match the results from small-scale laboratory granular avalanches and full-scale snow avalanches overtopping a dam. The data from these new experiments also match well this simple interpretation (with $a_{1}=10.5$ and $a_{0}=-5.6$ ), confirming the robustness of the scaling. In this paper, we focus on the function $f$ which could not be systematically calculated for all the data analyzed in Faug and others (in press) as $d_{0}$ and $V_{\mathrm{s}}$ were not simultaneously known.

\section{DEAD ZONE AND GRANULAR BORE}

The video camera at one side-wall of the channel allowed us to determine the evolution of free surface vs time in the vicinity of the obstacle. We observed the formation of a granular deposit propagating upstream of the dam, which could generate a 'bore' for high dams. First, we describe in detail the observed process highlighting a change in behaviour at $H_{\text {obs }} / h_{0} \sim 3$. Second, we try to quantify this change in behaviour by analyzing the propagation speed of the free surface for a given altitude inside the flow.

\subsection{Qualitative analysis of the deposition process upstream of the dam}

When the granular flow hit the dam, we observed two different regimes depending on the obstacle height. For low dams, a large amount of the incoming granular mass was able to overflow the obstacle while another portion was simultaneously blocked upstream of the dam (see Fig. 4a). The dead zone that formed upstream of the dam acted as a springboard for the granular mass overtopping the dam. For high dams,

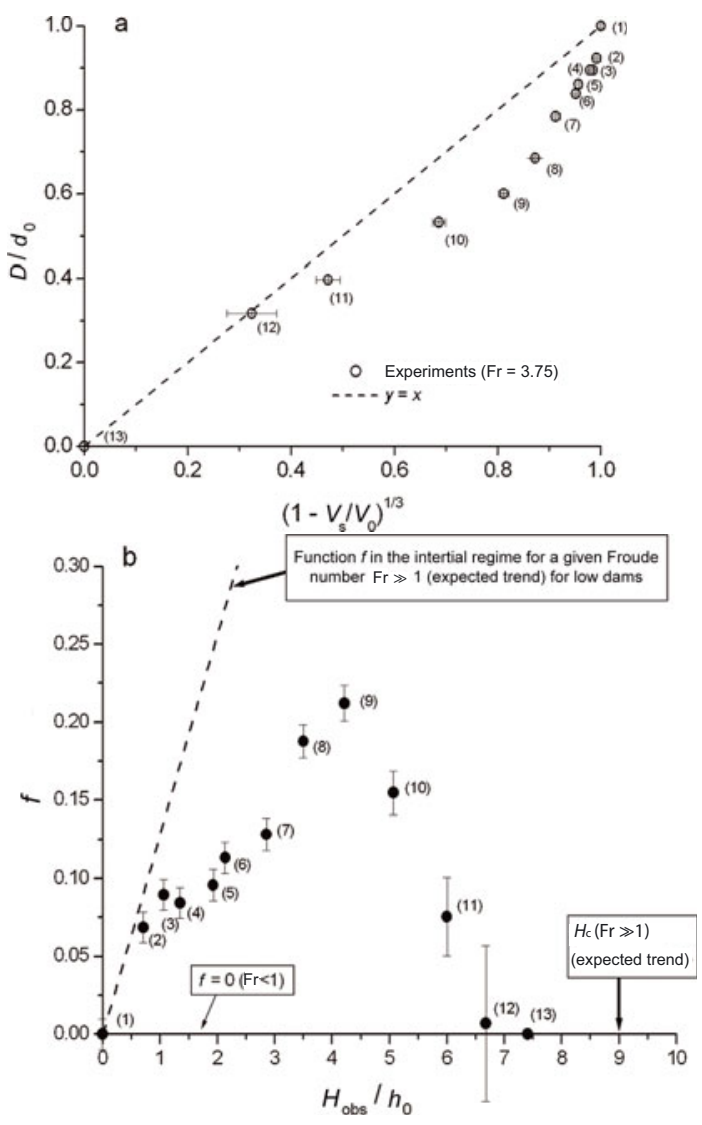

Fig. 3. (a) Run-out shortening $D / d_{0}$ vs volume reduction $(1-$ $\left.V_{s} / V_{0}\right)^{1 / 3}$. (b) Function $f$ vs dam height $H_{\text {obs }}$ relative to the incoming flow depth $h_{0}$.

we observed a time delay to fill the dam. The incoming flow was blocked for a long time and the granular deposit was able to propagate far upstream of the dam, forming a granular bore (see Fig. 4b).

We estimated the time when the granular flow started to overflow the dam, $t_{\text {ovr }}$. The origin of time was defined by the time when the particles at the front of the granular flow hit the dam, $t_{\mathrm{imp}}=0 . t_{\mathrm{ovr}}$ is depicted in Figure $4 \mathrm{c}$ as a function of the obstacle height ratio $H_{\text {obs }} / h_{0}$. The change in regime due to a strong limitation of the flux over the dam is captured well by Figure 4c. When $H_{\text {obs }} / h_{0}<2.9$, the impact and the overflow were simultaneous, i.e. $t_{\mathrm{ovr}}=t_{\mathrm{imp}}=0$. When the dam height was increased (i.e. $H_{\mathrm{obs}} / h_{0}>2.9$ ), $t_{\text {ovr }}$ demonstrated a large increase.

\subsection{Change in behaviour}

The image-processing method (using Image and MATLAB ${ }^{\mathrm{TM}}$ ) allowed us to track with time: (1) the frontier between the approximately immobilized grains (allowing the definition of the dead zone); (2) the free surface at the foreground sidewall; and (3) the free surface at the side-wall behind. These frontiers are represented in Figure $5 b$ by lines (1), (2) and (3). We chose a height $y=Y_{0}$ inside the flow, where $y$ is measured normal to the channel bottom as illustrated in Figure $5 \mathrm{~b}$. It was then easy to follow point $\mathrm{P}$ (see Fig. 5b) which represents the intersection between the free surface of the flow and a line parallel to the channel bottom at the chosen height $y=Y_{0}$.

Figure 5a depicts a typical result for a given $Y_{0}$ (here, $Y_{0}=$ $h_{0}$ ). It provides the distance $x$ travelled by the point $P$ in the 


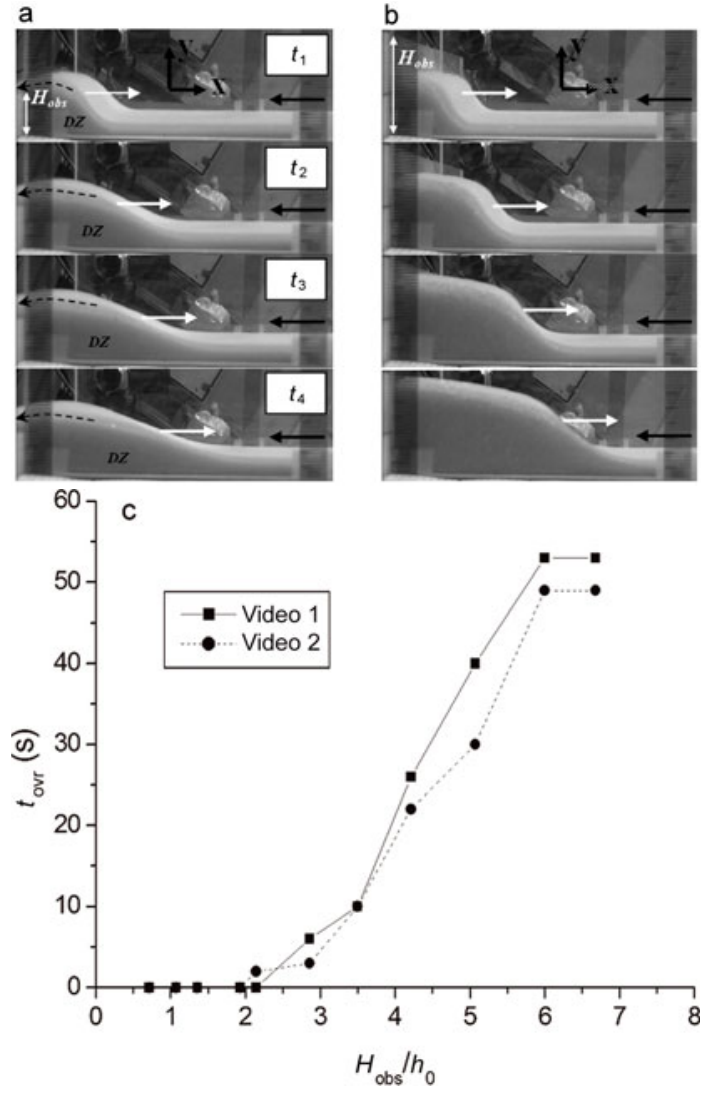

Fig. 4. Example of (a) the overflow regime for $H_{\text {obs }} / h_{0}=2.1$ where the dashed black arrow indicates the overflow $(\mathrm{DZ}=$ dead zone acting as a springboard); (b) the granular bore regime for $H_{\text {obs }} / h_{0}=5$ where the black (white) arrow indicates the direction of the incoming flow (propagation of the granular deposit); and (c) time $t_{\mathrm{ovr}}$ needed to fill the dam (before overflow) vs $H_{\text {obs }} / h_{0}$. Time $t_{\text {ovr }}$ was estimated from two video cameras located (1) at one side-wall of the channel and (2) downstream and overhanging the dam; the two methods yield a similar trend.

direction $x$ parallel to the channel bottom for a given $Y_{0}$. We observed that all experimental curves coincided when the dam height was greater than a critical value $H_{\mathrm{c}}$ defined experimentally by $2<H_{\mathrm{c}} / h_{0}<3$.

If we restrict our analysis to very short times in comparison to $t_{\mathrm{ovr}}(x$ reaches the maximum value at $t<2 \mathrm{~s}$ for low dams), the curves displayed in Figure 5a are lines that can be approximated by

$$
x=\alpha t+\beta,
$$

where $\alpha$ and $\beta$ are parameters that are expected to depend on $H_{\text {obs }}$. The parameter $\alpha$ may be interpreted as the speed of point $\mathrm{P}$ (Fig. $5 \mathrm{~b}$ ) in the direction $x$ :

$$
\alpha=\frac{x-\beta}{t} .
$$

Figure 6a depicts $\alpha$ vs the ratio $H_{\text {obs }} / h_{0}$ for $y / h_{0}=0.7,1$, $1.2,1.8$. These curves were obtained from point $\mathrm{P}$ on the free surface at the foreground side-wall (line (2) in Fig. 5b) for three values of $y / h_{0}$. $\alpha$ clearly indicates the change in behaviour already suggested by Figure 4c. $\alpha$ increases with the dam height and reaches an asymptotic value when $3 \lesssim H_{\text {obs }} / h_{0} \lesssim 4$. The curve obtained from the analysis of the propagation of the granular deposit (from a point $\mathrm{P}$ on line (1) defined in Fig. 4b) gives the same features for the
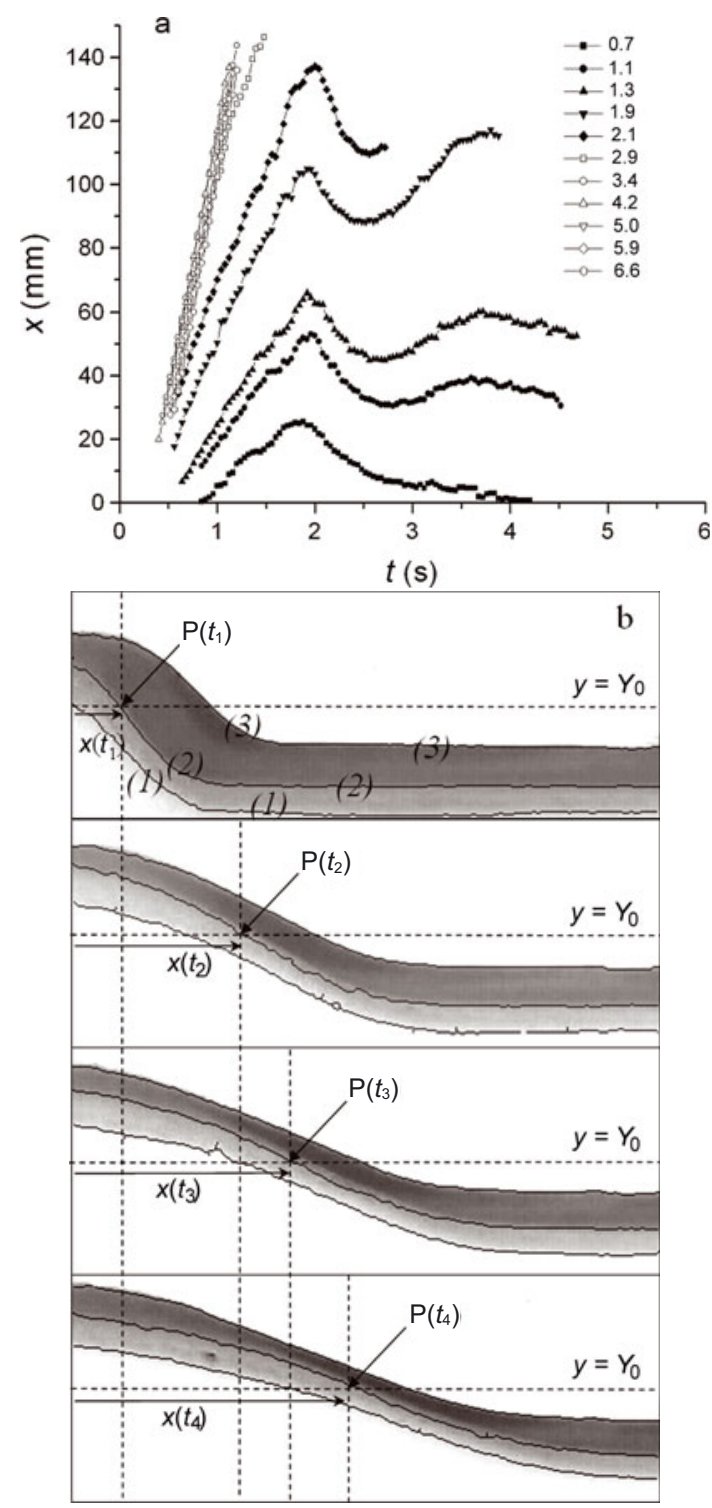

Fig. 5. (a) Distance $x$ travelled along the channel and upstream of the dam by the granular deposit vs time $t$ for different obstacle height ratios $\left(H_{\mathrm{obs}} / h_{0}\right)$ for $y / h_{0}=1$. (b) Definition of point $\mathrm{P}$, the intersection between the free surface and a line at height $y=Y_{0}$, where $y$ is measured normal to the bottom. These images were extracted from Figure $4 a$. See text for boundary definitions.

value $\alpha$ as shown by the square white symbols in Figure 6a. Figure $6 \mathrm{~b}$ gives the fitted $\beta$ value vs the ratio $H_{\text {obs }} / h_{0}$ for $y / h_{0}=0.7,1,1.2,1.8 . \beta$ increases with the dam height, reaches a maximum value when $2 \lesssim H_{\text {obs }} / h_{0} \lesssim 3$ and then decreases. Even though it is more difficult to give a physical meaning to $\beta$, it also reflects this change in behaviour.

The curves in Figure 6 highlight a change in behaviour for $H_{\text {obs }} / h_{0} \sim 3$. At this stage, it remains difficult to explain this change in behaviour quantitatively or in detail. However, we believe that it highlights a transition from an overflow regime for low dams to a granular bore regime for higher dams.

In the overflow regime, a large amount of the incoming granular mass is able to overflow the dam, preventing the upstream propagation of a granular bore. The incoming mass flows over the dead zone which acts as a springboard, probably minimizing the local energy dissipation. In the granular bore regime, a large amount of granular material is gradually 

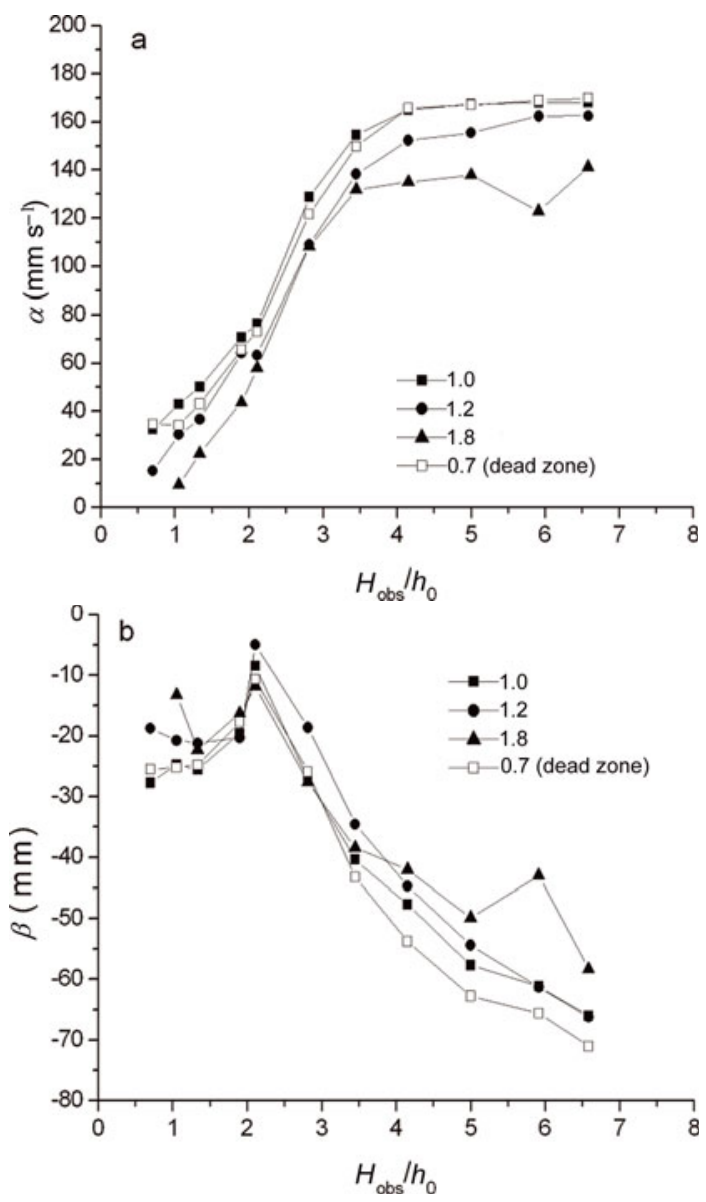

Fig. 6. (a) The $\alpha$ fitted values vs the normalized dam height $H_{\text {obs }} / h_{0}$ for different values of $y / h_{0}$. (b) The $\beta$ fitted values vs the normalized dam height $H_{\text {obs }} / h_{0}$ for different values of $y / h_{0}$. In each graph, the value $y / h_{0}=0.7$ was obtained from measurements at the frontier between the approximately immobilized grains and the moving grains (line (1) in Fig. 5b). The values $y / h_{0}=1,1.2,1.8$ were extracted from measurements at the free surface of the flow at the foreground side-wall (line (2) in Fig. 5b).

deposited upstream of the dam, and a granular bore is able to propagate far upstream of the obstacle.

This transition has a direct influence on the function $f$ and consequently on the run-out shortening downstream of the dam. It should be noted that $f$ demonstrated an inflection point towards $H_{\mathrm{obs}} / h_{0} \sim 3$ (Fig. $3 \mathrm{~b}$ ), corresponding to the value at which $\alpha$ and $\beta$ demonstrated a change in behaviour. Note that the asymptotic decrease in $f$ observed for $H_{\text {obs }} / h_{0}>5$ does not appear on the curves $\alpha\left(H_{\text {obs }} / h_{0}\right)$ and $\beta\left(H_{\text {obs }} / h_{0}\right)$. This result is unsurprising in that the $\alpha$ and $\beta$ parameters were deduced from the analysis of the upstream propagation phase $(t<2 \mathrm{~s})$, whereas the asymptotic behaviour $\left(V_{\mathrm{s}} / V_{0} \rightarrow 1\right)$ was observed for longer times $(t \gg 2 \mathrm{~s})$. Therefore, $\alpha$ and $\beta$ cannot capture the asymptotic behaviour of $f$ in Figure $3 \mathrm{~b}$.

\section{DISCUSSION AND CONCLUSION}

We have presented experiments on granular avalanches over a dam. We measured the maximum avalanche run-out downstream of the dam and the final volume retained upstream of the dam. In the avalanche regime studied here, we showed that the volume reduction generated by the obstacle was not sufficient to explain the run-out shortening due to the obstacle. The difference, in terms of run-out shortening, was interpreted as complex local energy dissipation which we describe using a function $f$. The evolution of $f$ vs the obstacle height $H_{\text {obs }}$ demonstrated two changes in behaviour for critical obstacle heights $H_{\mathrm{c} 1}$ and $H_{\mathrm{c} 2}$. For high obstacle heights, the volume retained upstream of the dam became close to the volume initially released, which explains why the function $f$ vanished above $H_{\mathrm{obs}}=H_{\mathrm{c} 2}$.

We also analyzed in detail the overflow and the granular deposit propagating upstream of the dam. It allowed us to identify a change in behaviour at an obstacle height close to $H_{\mathrm{c} 1}$. We highlighted a transition from an overflow regime to a granular bore regime at the critical height $H_{\mathrm{c} 1}$. The granular bore propagating far upstream of the dam, preventing a rapid overflow $\left(H_{\mathrm{obs}}>H_{\mathrm{c} 1}\right)$, is expected to dissipate much more energy than the dead zone which acts as a springboard for the overflowing mass $\left(H_{\mathrm{obs}}<H_{\mathrm{c} 1}\right)$.

The main result of this study is to show that the deposition process occurring upstream of the dam has a direct influence on the local energy dissipation (estimated from $f$ ) and therefore on the run-out shortening caused by the dam. This result offers interesting perspectives concerning the effectiveness and the optimal design of protection dams against full-scale snow avalanches at intermediate Froude numbers.

\section{ACKNOWLEDGEMENTS}

We thank H. Bellot, F. Ousset and C. Schlosser for their help in conducting the laboratory experiments and analyzing the data. We are also indebted to the two reviewers for their help in improving the paper.

\section{REFERENCES}

Chiou, M.-C., Y. Wang and K. Hutter. 2005. Influence of obstacles on rapid granular flows. Acta Mech., 175(1-4), 105-122.

Chu, T., G. Hill, D.M. McClung, R. Ngun and R. Sherkat. 1995. Experiments on granular flows to predict avalanche runup. Can. Geotech. J., 32(2), 285-295.

Cui, X., J.M.N.T. Gray and T. Jóhannesson. 2007. Deflecting dams and the formation of oblique shocks in snow avalanches at Flateyri, Iceland. J. Geophys. Res., 112(F4), F04012. (10.1029/2006JF000712.)

Domaas, U. and C.B. Harbitz. 1998. On avalanche run-up heights on deflecting dams: centre-of-mass computations compared to observations. In Hestnes, E., ed. 25 Years of Snow Avalanche Research, Voss, Norway, 12-16 May 1998. Proceedings. Oslo, Norwegian Geotechnical Institute, 94-98. (NGI Publication 203.)

Faug, T., P. Lachamp and M. Naaim. 2002. Experimental investigation on steady granular flows interacting with an obstacle down an inclined channel: study of the dead zone upstream from the obstacle. Application to interaction between dense snow avalanches and defence structures. Natur. Hazards Earth Syst. Sci. (NHESS), 2(3/4), 187-191.

Faug, T., M. Naaim, D. Bertrand, P. Lachamp and F. Naaim-Bouvet. 2003. Varying dam height to shorten the run-out of dense avalanche flows: developing a scaling law from laboratory experiments. Surv. Geophys., 24(5-6), 555-568.

Faug, T., M. Naaim and F. Naaim-Bouvet. 2004a. An equation for spreading length, center of mass and maximum run-out shortenings of dense avalanche flows by vertical obstacles. Cold Reg. Sci. Technol., 39(2-3), 141-151.

Faug, T., M. Naaim and F. Naaim-Bouvet. 2004b. Experimental and numerical study of granular flow and fence interaction. Ann. Glaciol., 38, 135-138. 
Faug, T., M. Naaim and A. Fourriére. 2007. Dense snow flowing past a deflecting obstacle: an experimental investigation. Cold Reg. Sci. Technol., 49(1), 64-73.

Faug, T., P. Gauer, K. Lied and M. Naaim. In press. Overrun length of avalanches overtopping catching dams: cross-comparison of small-scale laboratory experiments and observations from fullscale avalanches. J. Geophys. Res. (10.1029/2007JF000845.)

Gray, J.M.N.T. and X. Cui. 2007. Weak, strong and detached oblique shocks in gravity-driven granular free-surface flows. J. Fluid Mech., 579, 113-136.

Gray, J.M.N.T., Y.-C. Tai and S. Noelle. 2003. Shock waves, dead zones and particle-free regions in rapid granular free-surface flows. J. Fluid Mech., 491, 161-181.

Groupement de Recherche Milieux Divisés (GDR MiDi). 2004. On dense granular flows. Eur. Phys. J. E., 14(4), 341-365.

Hákonardóttir, K.M. and A.J. Hogg. 2005. Oblique shocks in rapid granular flows. Phys. Fluids, 17, 077101. (10.1063/1.1950688.)

Hákonardóttir, K.M., T. Jóhannesson, F. Tiefenbacher, and M. Kern. 2001. A laboratory study of the retarding effect of breaking mounds in 3, 6 and $9 \mathrm{~m}$ long chutes. Reykjavík, Veðurstofa Íslands. (Tech. Rep., VÍ-G01007-ÚR02.)

Hákonardóttir, K.M., A.J. Hogg, T. Jóhannesson and G.G. Tómasson. 2003a. A laboratory study of the retarding effects of braking mounds on snow avalanches. J. Glaciol., 49(165), 191-200.

Hákonardóttir, K.M., A.J. Hogg, T. Jóhannesson, M. Kern and F. Tiefenbacher. 2003b. Large-scale avalanche braking mound and catching dam experiments with snow: a study of the airborne jet. Surv. Geophys., 24(5-6), 543-554.

Harbitz, C.B., U. Domaas and A. Engen. 2000. Design of snow avalanche deflecting dams. In Zollinger, F. and G. Fiebiger, eds. Proceedings of the 9th Interpraevent Congress, 2630 June 2000, Villach, Austria. Vol. 1. Klagenfurt, Schutz des Lebensraumes vor Hochwasser, Muren und Lawinen, 383-396.
Irgens, F., B. Schieldrop, C.B. Harbitz, U. Domaas and R. Opsahl. 1998. Simulations of dense-snow avalanches on deflecting dams. Ann. Glaciol., 26, 265-271.

Jóhannesson, T. 2001. Run-up of two avalanches on the deflecting dams at Flateyri, northwestern Iceland. Ann. Glaciol., 32, 350-354.

Larsen, J.O. and H. Norem. 1996. The effect of dam constructions as mitigative measures. 14 years of experience from a full scale project. In Golovanov, V., ed. Proceedings of the International Conference on Avalanches and Related Subjects, Kirovsk, Russia, 2-6 September 1996. Apatit, Apatit Media, 59-65.

Lied, K., A. Moe, K. Kristensen, and D. Issler. 2002. Full scale avalanche test site and the effect of the catching dam. Oslo. Norwegian Geotechnical Institute. (NGI Rep. 581200-35.)

McClung, D.M. and A.I. Mears. 1995. Dry-flowing avalanche run-up and run-out. J. Glaciol., 41(138), 359-372.

Naaim, M. 1998. Dense avalanche numerical modeling: interaction between avalanche and structures. In Hestnes, E., ed. 25 Years of Snow Avalanche Research, Voss, Norway, 12-16 May 1998. Proceedings. Oslo, Norwegian Geotechnical Institute, 187-191. (NGI Publication 203.)

Naaim, M., T. Faug and F. Naaim-Bouvet. 2003. Dry granular flow modelling including erosion and deposition. Surv. Geophys. 24(5-6), 569-585.

Naaim, M., F. Naaim-Bouvet, T. Faug and A. Bouchet. 2004. Dense snow avalanche modeling: flow, erosion, deposition and obstacle effects. Cold Reg. Sci. Technol., 39(2-3), 193-204.

Platzer, K.M., S. Margreth and P. Bartelt. 2004. Granular flow experiments to investigate dynamic avalanche forces for show shed design. In Bartelt, P., E. Adams, M. Christen, R. Sack and A. Sato, eds. Proceedings of the Fifth International Conference on Snow Engineering, 5-8 July 2004, Davos, Switzerland. Leiden, etc., Balkema, 363-370.

Tai, Y.C., J.M.N.T. Gray, K. Hutter and S. Noelle. 2001. Flow of dense avalanches past obstructions. Ann. Glaciol., 32, 281-284. 